\title{
Toward A More Precise - and Accurate - View of Eco-Evolution
}

\author{
Ronald Bassar ${ }^{1}$, Tim Coulson ${ }^{2}$, Joseph Travis ${ }^{3}$, and David Reznick ${ }^{4}$ \\ ${ }^{1}$ Williams college \\ ${ }^{2}$ Oxford \\ ${ }^{3}$ Florida State University \\ ${ }^{4}$ University of California-Riverside
}

January 19, 2021

\begin{abstract}
Over the past fifteen years, the number of papers focused on "eco-evo dynamics" has increased exponentially (Figure 1). This pattern suggests the rapid growth of a new, integrative discipline. We argue that this overstates the case. First, the terms "eco-evo dynamics" and "eco-evo interactions" are used too imprecisely. As a result, many studies that claim to describe eco-evo dynamics are actually describing basic ecological or evolutionary processes. Second, these terms are often used as if the study of how ecological and evolutionary processes are intertwined is novel when, in fact, it is not. The result is confusion over what the term "eco-evolution" and its derivatives describe, a loss of appreciation for the history of genuine eco-evolutionary studies, and a loss of appreciation for the novelty associated with the original rise of the term. We advocate a more precise definition of eco-evolution that is more useful in our effort to understand and characterize the diversity of ecological and evolutionary processes and that focuses attention on the subset of those processes that offer novel results.
\end{abstract}

\section{Hosted file}

EcoEvoEcolLets2021-01-18 submitted.pdf available at https://authorea.com/users/379437/ articles/504771-toward-a-more-precise-and-accurate-view-of-eco-evolution 